\title{
Alimentos Geneticamente Modificados: Aspectos Regulatórios e de Saúde Pública ${ }^{(*)}$
}

\author{
REGULATORY AND PUBLIC HEALTH TOPICS \\ OF GENETICALLY MODIFIED FOODS
}

\section{RESUMO}

Historicamente, o homem vem modificando os alimentos com a finalidade de aumentar a produção e também suas qualidades nutricionais. $O$ uso da biotecnologia tornou possível esse propósito. Pela modificação genética dos organismos foi possível a inserção de características previamente selecionadas em uma determinada variedade de alimento. Essa nova metodologia tem gerado controvérsias e expectativas entre os consumidores bem como na comunidade cientifica e órgãos reguladores. Como forma de minimizar os efeitos oriundos da entrada destes produtos tecnológicos no País, os órgãos reguladores Brasileiros propuseram normas com a finalidade de garantir o direito à informação e assegurar a integridade da saúde do consumidor. Neste estudo foi realizada a revisão e análise crítica da literatura, sobre os organismos geneticamente modificados e dos alimentos transgênicos, bem como um levantamento das normas que se referem a esses organismos e as penalidades previstas quando da não observância dessas normas.

(*) (http://www.brasil.gov.br/em questão. Editado pela Secretaria de Comunicação de Governo e Gestão Estratégica da Presidência da República; Data do acesso: 29.9.2003).

$\left.{ }^{* \star}\right)$ Advogada Especialista em Direito Penal pela Faculdade de Ciências Sociais Aplicadas de Cascavel. $\left(^{\star * \star}\right)$ Professor Associado, Faculdade de Saúde Pública, USP.

$\left({ }^{\star \star \star \star}\right)$ Advogado e Professor da Universidade Estadual do Oeste do Paraná - Unioeste - Campus de Marechal Cândido Rondon.

$\left({ }^{\star \star \star \star \star}\right)$ Professora Doutora, Faculdade de Saúde Pública, USP. Autor para correspondência: Dra. Maria Helena Matté, Avenida Dr. Arnaldo, 715, Cerqueira César, 01246-904, SP/SP. E-mail: mhmatte@usp.br Entrada: 5.7.2003. Aprovado: 24.9.2004. 


\section{Descritores}

Alimentos Transgênicos, OGM, Biossegurança, Princípio da Precaução, Segurança Alimentar.

\section{ABSTRACT}

Historically men have modified their food in order to provide an increase in the production and a better nutritional quality. The use of biotechnology has made possible this purpose. By the genetic modification of organisms it was possible the insertion of previously selected characteristics in to a determined variety of food. This new methodology has generated controversy and expectations among food consumers as well as in the scientific community and regulatory organs. To minimize the effects caused by the entrance of these technologic products in the country, Brazilian legislative organs have proposed rules in order to guarantee the right to information and to assure health integrity of the consumers. In this study a review and critical analyses of the literature of genetically manipulated organisms and transgenic food was made, as well as the survey of regulations referred to these organisms and the penalties applied in the non-observation of these rules.

\section{Key-words}

Transgenic foods, GMO, risk assessment, biosafety, precautionary principle, food safety.

\section{INTRODUÇÃO}

O direito à saúde além de dever do Estado é um direito social, previsto pela Carta Magna, complementado pela Lei n. 8.080, de 19.9.1990, (Lei Orgânica da Saúde), em que em seu art. $3^{\circ}$ dispõe os fatores determinantes da saúde, sendo que ao Estado compete reger e verificar o cumprimento destes direitos.

A existência de outros dispositivos legais vem assegurar que o direito à saúde seja garantido, normatizando, regulando, e em alguns casos complementando o documento original. As normas editadas pelo ministério do meio ambiente e da agricultura, bem como as dos órgãos de vigilância sanitária, são exemplos destes dispositivos.

Ainda, complementando o grupo de preceitos legais, o código de defesa do consumidor regulamenta os casos de inobservância das normas supra citadas, e também serve como amparo legal onde existem lacunas ou ausência de dispositivos regulamentadores, atinentes a produtos e serviços dispostos no mercado. 
Existem, porém, situações em que o conhecimento científico é insuficiente, para determinar a possibilidade da existência de riscos à saúde e ao meio ambiente, decorrentes de procedimentos biotecnológicos. Faz-se então necessário, nesses casos, que as autoridades dos órgãos legislativos lancem mão de um instrumento que direcione a tomada de decisões quanto às atividades em que é difícil precisar tais riscos, tanto para estabelecer normas quanto para coibir tais atividades. Este instituto é denominado Princípio da Precaução.

Desde o início da humanidade, quando o homem começou a utilizar a terra como fonte de subsistência até os dias atuais, diversas modificações ocorreram na forma e no modo de produção de alimentos. As fontes de alimentos disponíveis ao homem, tanto animal como vegetal, evoluíram através de uma seleção natural gerando uma diversidade genética por meio de mudanças espontâneas.

Embora consideráveis avanços tenham sido alcançados nos processos de produção de alimentos, existem limites em quanto pode ser alcançado por meio dos métodos convencionais de seleção. Novas metodologias com base na biotecnologia geraram considerável interesse devido à rapidez e precisão das mudanças genéticas que podem ser introduzidas nos processos de produção principalmente de alimentos para consumo humano.

Porém, a chegada desta nova era gerou incertezas por parte da comunidade científica e dos organismos reguladores, devido ao pouco tempo de avaliação sobre eventuais efeitos adversos que venham ocorrer na população consumidora ou mesmo ao meio ambiente. Observa-se ainda, uma intensificação do grau de incerteza entre a população consumidora, a qual não dispõem de informação clara e compreensível sobre os Organismos Geneticamente Modificados.

Faz-se necessário, portanto, regulamentar as atividades de produção, distribuição e comercialização de produtos oriundos de processos biotecnológicos, criando formas de garantir a observância dessas novas normas para que o acesso a estes produtos não represente um risco à saúde da população.

É imperioso, portanto, que haja o amplo conhecimento de tais normas, para que todos os envolvidos nas atividades em questão possam estar enquadrados dentro do regulamento legal.

\section{ALIMENTOS TRANSGÊNICOS E GENETICAMENTE MODIFICADOS}

Historicamente, o homem tem modificado profundamente a forma e as características da maioria das espécies cultivadas. Estas mudanças foram amplamente realizadas com o intuito de promover uma melhor adap- 
tação e aumento de produtividade num contexto de campos cultivados em contraste ao ambiente natural, de forma que as metodologias disponiveis para atingir tais melhorias, fossem elas aumento da produtividade ou mudanças na qualidade dos alimentos, cresceram dramaticamente em número e sofisticação técnica $(7,8)$.

Por meio de mutantes naturais, novas e importantes características representaram por muito tempo, a mais simples e primitiva forma de modificação genética realizada por gerações de agricultores $(8,28)$. Porém, somente em décadas recentes, as modificações genéticas embasadas em métodos científicos foram amplamente desenvolvidas graças à contribuição da biotecnologia.

Com o advento da biotecnologia moderna uma crescente variedade de técnicas, procedimentos e processos, dentre elas a tecnologia de DNA recombinante, passaram a ser aplicados na produção de alimentos os quais podem substituir ou ainda complementar a biotecnologia clássica (7).

A OECD (Organisation for Economic Co-operation and Development), em 1992, conceitua biotecnologia como sendo a aplicação de conceitos científicos e de engenharia no processamento de material através de agentes biológicos com a finalidade de oferecer bens e serviços (34).

O desenvolvimento inicial da biotecnologia aplicada a alimentos enfocou a modificação genética de microrganismos produtores de enzimas para aplicação na produção de alimentos. A área com maior ênfase é a de desenvolvimento de uma ampla variedade de culturas modificadas para conter determinadas características tais como resistência a herbicidas, insetos e vírus. Adicionalmente, demonstrando grandes perspectivas, podem ser realizadas alterações na composição desses produtos com a finalidade de extensão do tempo de conservação ou mesmo da alteração do conteúdo nutricional (7).

Para melhor compreensão deste tema faz-se necessário definir os termos organismos geneticamente modificados (OGM) e organismos transgênicos. Os primeiros são aqueles organismos, sejam eles animais, vegetais, bactérias ou vírus, que tenham sofrido alguma alteração no seu conteúdo genético, sendo essa por processos naturais ou por intermédio de métodos laboratoriais. Já os organismos transgênicos são aqueles que sofreram alteração no seu conteúdo genético por meio da introdução de material genético oriundo de uma outra espécie (46).

A transgênese oferece, portanto, a possibilidade da introdução de genes originários de praticamente qualquer organismo vivo para células de um outro organismo, processo esse denominado de transformação. No caso das células vegetais essa habilidade é apenas mais uma adição a uma longa lista de métodos que visam ampliar a diversidade genética disponível em determinadas espécies de plantas (7). 
Dos produtos alimentícios oriundos de manipulação genética vale ressaltar que o tomate foi o primeiro produto geneticamente modificado disponibilizado para comercialização. Desde então diversas outras culturas geneticamente engenheiradas foram aprovadas pelas autoridades dos Estados Unidos e outros países $(12,21)$.

Este tipo de tecnologia serve a dois diferentes propósitos: O primeiro refere-se à introdução de marcadores selecionados, que irão conferir ao organismo modificado, uma característica previamente conhecida e distinta a qual é utilizada para diferenciar o novo organismo de um universo de organismos não modificados. Uma vez que este marcador deixa de ter utilidade após a produção da planta transgênica, e ainda devido ao receio de que genes marcadores possam representar um risco adicional a ser gerado pela nova planta, existe uma ansiedade em eliminar estes genes marcadores das plantas transgênicas $(7,16,25,39,41,46)$.

O segundo propósito é introduzir, no organismo a ser modificado, genes que venham conferir determinadas características, ou ainda, melhorias na qualidade nutricional desses alimentos (7).

Diversas características têm sido alvo de interesse na transgênese de plantas, destinadas à utilização como alimento para consumo humano. Plantas como o tomate, milho, soja, canola, cana de açúcar e outros foram geneticamente modificados para a obtenção de característica de resistência a pragas, produção de vacinas e produtos imunogênicos como anticorpos, resistência a determinados herbicidas, e ainda melhoria de qualidade nutricional $(7,11,17,18,19,40)$.

Independente do método utilizado para a transformação de plantas, seja ela através de um vetor biológico ou por introdução mecânica do gene de interesse, não existem meios de controlar o número de cópias introduzidas ou mesmo a localização precisa do referido material genético no genoma alvo, de forma que as linhagens obtidas com a mesma construção genética, não necessariamente serão idênticas devido à expressão da transgênese que pode ser diferenciada seja pelo número de cópias seja devido ao efeito da localização do material genético introduzido $(7,45,46)$.

Advindo da realidade atual dos alimentos geneticamente modificados, principalmente ao que se refere às estratégias de identificação e reconhecimento destes produtos, faz-se necessário que os métodos de detecção e quantificação sejam sensíveis e apropriados de modo a detectar alvos que sejam estáveis e que não sofram grandes alterações durante o processo de produção do alimento em questão.

Importante aspecto a ser ressaltado no que se refere à detecção e quantificação de produtos geneticamente modificados, principalmente os transgênicos, é a relação destes procedimentos com a aplicação das normas reguladoras, e com a informação da presença dos organismos gene- 
ticamente modificados em produtos disponíveis para comercialização. Ao consumidor final destes produtos é assegurado o direito à informação, e ainda normas existentes no tocante à rotulagem, expressam claramente quantidades máximas toleradas de organismos geneticamente modificados em produtos comercializados em diversos países do mundo (26).

Fica evidente, portanto, a relevância não somente econômica, mas também social dos alimentos geneticamente modificados e transgênicos, visto que estes significam a possibilidade de acesso inovador e realístico às tecnologias que venham a facilitar um aumento na produção de alimentos para distribuição igualitária. Digno de nota, também, é a perspectiva de acesso a produtos com maior valor nutricional que podem ser produzidos através de métodos biotecnológicos.

O aumento do plantio comercial de culturas geneticamente modificadas tem, em contrapartida, elevado a conscientização pública quanto à introdução de alimentos geneticamente modificados na cadeia alimentar (7).

Dessa conscientização, suscitou a hipótese do surgimento de novas pragas originadas de insetos resistentes a plantas modificadas para produzirem substâncias pesticidas. Essa resistência seria conseguida através do incremento da pressão na seleção de organismos resistentes ao produto gerado pela planta geneticamente modificada $(4,10,40)$.

Outra preocupação da comunidade científica trata da transferência de genes no ambiente por meio de transformação, possibilitando que o material genético seja transferido para uma bactéria presente naturalmente nesse ambiente. Todo esse processo, porém, depende da disponibilidade de material genético remanescente no solo, resultante da morte celular ou rompimento da parede da célula que possui uma transgene, a qual pode ser preservada nesse ambiente por longo período de tempo devido à proteção proporcionada por grãos de areia ou argila $(9,46)$.

Outra forma de aplicação de plantas transgênicas na cadeia alimentar visa a disponibilização de componentes que venham a induzir a imunidade a determinadas doenças. Embora este tipo de aplicação tenha sua importância ressaltada devido à atividade "vacinal" deste tipo de produto, estudos demonstraram que a disponibilidade desses fatores imunizadores, os quais deverão ser introduzidos pela via alimentar, não são acessíveis em quantidades suficientes para induzir a atividade esperada (11). Por outro lado, a aplicação da biotecnologia e da transgênese para desenvolver plantas que produzem substâncias que possam ser purificadas e concentradas com a finalidade médica já foi reconhecida como uma atividade que pode representar grande interesse para a área da saúde $(11,18)$.

Não se deve deixar de lado, porém, a necessidade de estudos complementares contemplando a utilização de produtos geneticamente modificados bem como seus efeitos sejam eles desejáveis ou decorrentes da 
metodologia de criação, que venham a contribuir com a avaliação de riscos que possam porventura acompanhar o consumo e utilização destes alimentos e seus subprodutos para a criação de normas reguladoras que embasem as decisões políticas e científicas originadas da nova tecnologia empregada $(42,45)$.

\section{OGM E SAÚDE PÚBLICA}

Os impactos sobre a saúde humana ainda não estão estabelecidos, conforme leis elementares de biossegurança quando se trata de organismos geneticamente modificados. Estudos realizados demonstram que existe a possibilidade de desenvolvimento de alergias, em indivíduos suscetíveis, quando da ingestão de alimentos transgênicos. Exemplo clássico o qual não deve ser esquecido é o da soja modificada com a finalidade de introdução de genes da castanha-do-pará, o qual resultou em quadros de alergia, quando testada em determinados indivíduos (46).

Além do mais, efeitos não desejados provenientes, seja de múltiplas funções oriundas de um mesmo gene ou mesmo efeitos secundários deste gene, podem representar um risco ainda não exatamente determinado para a população. Existe ainda a possibilidade de mutagênese devido à transferência de genes destes produtos $(7,16,25,39,41,46)$.

Sob o ponto de vista da medicina, discute-se a possibilidade, da utilização das plantas transgênicas para o uso farmacêutico e industrial, como a produção de anticorpos, por terem várias vantagens como fonte de proteínas, se comparadas às proteínas derivadas do ser humano ou de animais. Além do mais, a grande vantagem nesse tipo de procedimento reflete-se no seu baixo custo de produção $(11,18)$.

Estudos realizados por especialistas discutem e analisam as expectativas e suas respectivas limitações. Em relação às expectativas, o estudo demonstra a possibilidade do desenvolvimento de uma vacina oral contra doenças gastrintestinais agudas, que é a segunda maior causa de morte no mundo. Foram feitas experiências com outros tipos de doenças, entre elas a cólera e verificou-se a necessidade da "overdose" da variedade de planta transgênica para se obter o resultado desejado $(9,11)$.

Sob o aspecto social, a engenharia genética ao produzir estas plantas geneticamente modificadas tenta solucionar um dos maiores problemas enfrentados no mundo todo, que é a fome (37).

Apesar de tudo, necessário se faz analisar os impactos decorrentes de tal tecnologia, avaliando questões tais como o meio ambiente, pois a modificação genética das plantas abre as portas para que toda uma biodiversidade se modifique, devido à pressão causada pela nova tecnologia. 
Além do aspecto ambiental, o aspecto econômico é de grande relevância, pois ao mesmo tempo em que as plantas transgênicas seriam a solução para a crise mundial da fome, a utilização de sementes modificadas, sujeitas ao pagamento dos direitos de exploração de patentes, pode elevar o custo de produção (37).

\section{IMPACTO AMBIENTAL}

A preocupação com o meio ambiente é de fundamental importância, e

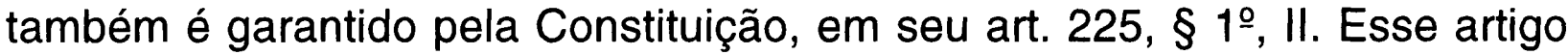
visa a proteção do meio ambiente, juntamente com seu ecossistema e seu equilíbrio natural.

A relação dos organismos geneticamente modificados com o meio ambiente é delicada no que concerne aos efeitos causados ao ecossistema. Esses efeitos, muitas vezes indesejáveis, podem afetar a biodiversidade, ocasionado o que é referido como "poluição genética". Como exemplo pode ser citado o caso da eliminação, por competitividade, de variedades que antes existiam naturalmente (33).

Questiona-se a possibilidade de haver o surgimento de insetos cada vez mais resistente às plantas transgênicas, visto que com a exposição cada vez maior e com a pressão seletiva, este pode ser induzido a sofrer uma evolução para poder continuar sobrevivendo (10). Além deste aspecto, o acasalamento entre estes insetos resistentes poderia gerar novos insetos resistentes, correndo-se o risco de criar uma espécie de praga super resistente a este determinado herbicida, obrigando desta forma a fortalecer cada vez mais os pesticidas. (33)

Apesar dos possíveis aspectos negativos que possam ocasionar ao meio ambiente, o uso desta tecnologia para aplicações em bioremediação, pode ser considerado como um aspecto positivo. Esse tipo de aplicação está em fase de desenvolvimento e busca amenizar os danos causados à natureza pelo homem, tais como a remoção de poluentes derivados de processos industriais, como é o caso do plástico(11).

\section{PRINCÍPIO DA PRECAUÇÃO}

O princípio da precaução foi precedido pelo princípio de Vorsorge na década de 70 , originário da Alemanha, devido à segunda guerra mundial, e também ao rápido desenvolvimento industrial, que causaram impactos, tanto na Saúde quanto no meio ambiente. Tal princípio tornou-se fundamental para a lei ambiental germânica, sendo que seu uso foi justificado para a adoção de políticas severas, responsáveis pelos cuidados com os proble- 
mas causados pela chuva ácida, pelo aquecimento global e com a poluição do Mar do Norte $(27,29,44)$.

A introdução do princípio da precaução deu-se em 1984, com a $1^{\text {a }}$ Conferência Internacional da Proteção do Mar do Norte, sendo que sua adoção se deu logo após a $2^{\text {a }}$ Conferência Internacional da Proteção do Mar do Norte, sendo posteriormente adotada por outros países por meio do Tratado de Maastricht, Convenção de Barcelona, Convenção de Mudanças Climáticas, entre outros $(20,22,23)$.

No ano de 1992, foi realizada a Conferência das Nações Unidas sobre Meio Ambiente e Desenvolvimento, na cidade do Rio de Janeiro. Tal Conferência adotou o princípio da precaução em seu artigo n. 15, onde conceitua e especifica o seu uso em relação ao meio ambiente.

Em 1996, a Suprema Corte da Índia em decisão ímpar, relatou que o princípio da precaução faria parte da lei costumeira ambiental internacional daquele país (38).

Este instituto é conceituado como sendo a garantia contra os riscos potenciais que, de acordo com o estado atual do conhecimento, não podem ser ainda identificados. Este Princípio afirma que a ausência da certeza científica formal, a existência de um risco de um dano sério ou irreversível requer a implementação de medidas que possam prever este dano.

Tal princípio tem como bases fundamentais clareza nas tomadas de decisões e a avaliação do risco, para que haja o exercício da democracia em todas as áreas, sejam elas ciências, saúde, ou qualquer que seja a área em que este instituto esteja envolvido $(14,20,22)$.

A entrada deste princípio no Brasil se deu devido à declaração do Rio de Janeiro sobre o meio ambiente e desenvolvimento, sendo apregoada também pela Instrução Normativa n. 24, de 10.10.2002, do Instituto Brasileiro do Meio Ambiente e dos Recursos Naturais Renováveis (IBAMA).

A área do direito ambiental faz uso de um princípio parecido, denominado princípio da prevenção, no qual este se diferencia do princípio da precaução pelo fato de que as conseqüências do ato serem conhecidas, enquanto que no princípio da precaução os efeitos ou conseqüências de tal ação não são conhecidos (2).

Nesse sentido, fica claro o papel do Estado em intervir junto à proteção ao meio ambiente, preservando a diversidade e a integridade do Patrimônio Público do país, tendo a obrigação de fiscalizar a pesquisa e a manipulação genética, assim como controlar a produção, comercialização e o uso de técnicas, métodos e substâncias que possam causar algum risco à saúde humana e ao meio ambiente (5).

Juntamente com a obrigação do Estado em intervir junto ao meio ambiente, a Lei n. 7.347/85 trata da responsabilização do agente que causar 
algum perigo que atinja o meio ambiente ou a saúde humana, independentemente de ação popular, visto que estes são bens maiores protegidos pela Carta Magna, sendo, portanto, dever do Estado garanti-los.

\section{EMBASAMENTO LEGAL}

Os organismos geneticamente modificados estão presentes desde 0 final dos anos 80, tendo sido desenvolvido nos Estados Unidos e Oeste da Europa (1). O Brasil começou a ter o domínio sob tal tecnologia a partir de meados dos anos 90 , onde houve a necessidade do país adaptar, assim como elaborar novos regulamentos com o objetivo de propor padrões de segurança, construção, cultivo, armazenagem, o uso, a comercialização e a liberação no meio ambiente deste tipo de organismo.

A CTNBio (Comissão Técnica Nacional de Biossegurança), órgão anexado ao Ministério da Ciência e Tecnologia foi instituído em 1995, pela Lei $n$. 8.974 com o objetivo de propor uma política de biossegurança, para acompanhar o desenvolvimento técnico e científico das diferentes áreas, objetivando a proteção do consumidor e da população em geral, com cuidados permanentes com a proteção ao meio ambiente, atmosfera, estabelecendo padrões e regulamentos em atividades e projetos que contenham construção, cultivo, manipulação, uso, transporte, armazenagem, comercialização, consumo, liberação e lançamento no meio ambiente dos organismos geneticamente modificados.

A Anvisa (Agência Nacional de Vigilância Sanitária) criada através da Lei n. 9.782/99 que definiu o Sistema Nacional de Vigilância Sanitária, é vinculada ao Ministério da Saúde. Sua principal finalidade, segundo o artigo sexto da lei, é proteger a saúde da população por meio do controle sanitário da produção e da comercialização de produtos e serviços submetidos à vigilância sanitária, inclusive dos ambientes, dos processos, dos insumos e das tecnologias a eles relacionados. Essa agência tem por escopo a normatização, controle e fiscalização de produtos, substâncias e serviços de interesse para a saúde, incluídos os organismos geneticamente modificados.

A Constituição Federal sofreu uma modificação, passando a prever a preservação do patrimônio genético, listado em seu art. $225, \S 1 \%$, II, visto que antes de sua promulgação (1988), não havia preocupações acerca da biotecnologia.

Complementando a lei da biossegurança, medidas provisórias e decretos expedidos pela CTNBio (Comissão Técnica Nacional de Biossegurança) e resoluções do Conselho Nacional do Meio Ambiente - CONA$M A$, versam sobre os experimentos em biotecnologia, e regulam seus procedimentos. 
Existem vários decretos que versam sobre a biotecnologia, tais como o Decreto n. 3.871/2001, que normatiza a rotulagem dos alimentos; Decreto n. 2.159/98, que vem a ser a convenção sobre a diversidade biológica sobre vinculação e composição da CTNBio; Decreto n. 2.577/98, que dá nova redação ao art. 3, do Decreto n. 1.752, de 20.12.1995, e o Decreto Legislativo n. 2, de 3.2.1994 - aprova o texto da Convenção sobre Diversidade Biológica, assinada durante a Conferência das Nações Unidas sobre Meio Ambiente e Desenvolvimento realizada na cidade do Rio de Janeiro, no período de 5 a 14 de junho de 1992.

Quanto às portarias que cuidam da biotecnologia são as de maior relevância: Portaria MCT n. 684, de 13.9.2000, que designa representantes, especialistas em biotecnologia da área da saúde, para compor a Comissão Técnica Nacional de Biossegurança - CTNBio; Portaria MCT n. 138, de 26.4.2000, que designa representantes, especialistas em biotecnologia da área ambiental, para compor a CTNBio; Portaria MCT n. 555, de 13.12.1999, que designa representantes do Ministério do Meio Ambiente para compor a CTNBio; Portaria MCT n. 409, de 17.9.1999, que designa representantes do Ministério da Agricultura e do Abastecimento para compor a CTNBio, e Portaria MCT n. 272, de 20.7.1995, que institui Comissão Interministerial com a finalidade de elaborar proposta de regulamentação da Lei n. 8.974/95.

As instruções normativas (IN) da CTNBio mais importantes são a IN n. 1, que dispõe sobre o requerimento e a emissão do Certificado de Qualidade em Biossegurança - CQB, e a instalação e o funcionamento das Comissões Internas de Biossegurança - CIBio; IN n. 3, que estabelece normas para a liberação planejada, no meio ambiente, de Organismos Geneticamente Modificados; IN n. 6, que estabelece normas sobre classificação dos experimentos com vegetais geneticamente modificados quanto aos níveis de risco e de contenção; IN n. 8, que dispõe sobre a manipulação genética e sobre a clonagem em seres humanos; IN n. 9, que estabelece normas sobre intervenção genética em seres humanos.

Em relação aos aspectos ambientais encontram-se as resoluções do Conama (Conselho Nacional do Meio Ambiente), onde as mais significativas são: Resolução n. 237 de 19.12.1997, que cuida do Licenciamento Ambiental e a Resolução Conama n. 1, de 23.1.1986, e que estabeleceu as diretrizes gerais para uso e implementação da Avaliação de Impacto Ambiental.

Nos Estados Unidos, a liberação de organismos geneticamente modificados no meio ambiente é controlado pelo USDA (United States Departament of Agriculture), onde qualquer liberação, tanto para testes ou outras propostas há a necessidade de se requerer uma autorização, descrevendo as modificações realizadas nas plantas, os métodos utilizados, as precauções tomadas para assegurar que o organismo geneticamente modificado não irá se espalhar no meio ambiente (21). 


\section{ROTULAGEM DOS ALIMENTOS E DIREITO DE INFORMAÇÃO}

A qualidade e a segurança dos alimentos são motivos de preocupação desde o momento em que estes se tornaram objetos de comercialização, onde a possibilidade de se adulterar produtos para uma maior obtenção de lucros, não importando os riscos à saúde pública são cada vez mais crescentes (3).

$O$ advento de novas tecnologias usadas para diminuir custos e minimizar os riscos das perdas decorrentes de pragas, doenças e fungos nas plantações traz implicações jurídicas no que diz respeito à comercialização do alimento industrializado, em que a necessidade de se divulgar o tipo de processamento do produto acaba se tornando um direito do consumidor final.

Nesse sentido, o código de defesa do consumidor acaba se tornando uma poderosa arma nas mãos da população, que a partir desse instrumento pode cobrar e exercer o seu direito de informação.

Em seu art. 6인, tal código traz que é um dos direitos básicos do consumidor a "informação adequada e clara sobre os diferentes produtos e serviços, com especificação correta de quantidade, características, composição, qualidade e preço, bem como sobre os riscos que apresentem".

Em complementação ao referido artigo, o art. 31 do mesmo código discorre sobre a informação pela via da publicidade, da rotulagem, que deve chegar ao consumidor para fazer com que este possa optar pela compra ou não do objeto a venda. A informação contratual é regida pelos arts. $46 \mathrm{e}$ segs. do mesmo dispositivo legal.

Em relação aos organismos geneticamente modificados, a lei não poderia ser mais clara. A informação de que se trata de um produto "diferenciado pela biogenética" deve fazer parte do rótulo, para que o consumidor possa exercer o seu direito de escolha, mesmo porque nem todos os consumidores são contra os alimentos geneticamente modificados.

Já quanto aos produtos importados, há necessidade de se regulamentar a entrada de produtos estrangeiros, assim como fazer a ampla fiscalização destes produtos, para que não haja injustiça para com os produtores nacionais, que são obrigados a informar o consumidor que seu produto se trata de um produto derivado de modificação genética.

Segundo Ahmed 2002(1), pelo menos $60 \%$ dos produtos alimentícios a venda nos supermercados dos Estados Unidos, são derivados de organismos geneticamente modificados.

Como esse país não regulamenta a questão da rotulagem, a entrada dos produtos alimentícios em outros países, tais como o Brasil, que, ape- 
sar do Decreto n. 4.680, de 24.4.2003, que regulamenta a questão do direito à informação quanto aos alimentos geneticamente modificados, deixa uma lacuna no que diz respeito aos alimentos importados, fazendo com que alimentos derivados de organismos geneticamente modificados entrem no mercado brasileiro, sem qualquer menção em sua rotulagem.

A preocupação com a rotulagem dos alimentos geneticamente modificados não é só Brasileira. No Sul da África existem leis que regulam a importação de geneticamente modificados através do Departamento de Saúde Nacional e Desenvolvimento Populacional, adotando o Codex Alimentarius nas questões pertinentes à rotulagem. A Argentina e o Chile têm legislação própria, assim como painéis que avaliam e autorizam o desenvolvimento comercial dos alimentos geneticamente modificados (28).

Taiwan importa a maioria dos alimentos consumidos, sendo que o milho e a soja são totalmente importados. Apesar disso, houve a promulgação da lei que regulamenta e obriga a constatação deste tipo de ingrediente no rótulo dos produtos (43).

Os Estados Unidos não tem uma lei específica que regule a questão da rotulagem, sendo que o Governo estimula a rotulagem voluntária, solicitando que as empresas notifiquem ao FDA (Food and Drug Administration) sobre suas pretensões comerciais pelo menos cento e vinte dias antes de fazer o lançamento em mercado (1).

$\mathrm{Na}$ Ásia, a legislação ainda é diversa, sendo que as plantações geneticamente modificadas são todas exportadas para a China e Austrália, sendo que na China não tem nenhuma legislação que regulamente a questão dos alimentos geneticamente modificados (28).

Por meio do Decreto n. 4.680/2003, todo e qualquer alimento que seja oriundo de organismos geneticamente modificados, seja animal, seja vegetal, deverão constar em seu rótulo, para que o consumidor tenha o direito à escolha do produto que ele está adquirindo.

O não cumprimento desta norma implica em aplicações sancionadoras dispostas no código de defesa do consumidor e demais normas aplicáveis, como é o caso da Lei n. 6.437 de 24.8.1977, que prevê sanções como advertência, multa, apreensão, inutilização, interdição, suspensão de vendas e/ou fabricação de produto, cancelamento de registro, interdição parcial ou total do estabelecimento, proibição de propaganda, cancelamento de autorização para funcionamento da empresa, cancelamento do alvará de licenciamento de estabelecimento.

A edição das Medidas Provisórias ns. 113 e 131, que foram, respectivamente, convertidas nas Leis ns. 10.688 de 13.6 .2003 e 10.814 de 15.12.2003, que liberaram a comercialização da safra de soja geneticamente modificada de 2003 e também o plantio até o dia 31 de dezembro daquele ano, as sementes de soja geneticamente modificadas da safra 2002/2003, que fo- 
ram guardadas pelos produtores para uso próprio, além de estabelecer normas para o plantio e comercialização da produção de soja da safra 2003/ 2004, favorecendo cerca de 150 mil produtores rurais do Rio Grande do Sul que plantavam ilegalmente essas sementes, bem como assegurando o plantio de sementes remanescentes no ano de 2003.

Essa "legalização do ilegal" demonstra tanto a dificuldade de fiscalização sanitária desse tipo de atividade, bem como a pressão econômica subjacente movida pelo interesse na expansão desse tipo de mercado, que não obstante os benefícios anunciados estão sujeitas ao pagamento dos direitos de exploração de patentes.

\section{DISCUSSÃO}

O surgimento de tecnologias que viabilizem um baixo custo de produção, assim como a possibilidade de se reduzir problemas relacionados à agricultura, como é o caso das pragas difundidas nas lavouras, assim como a viabilização de resolução de problemas relacionados a nível mundial, como é o caso da fome, é motivo de grande questionamento em todas as esferas, sejam elas legais, científicas ou sociológicas.

A legislação brasileira adota o uso do princípio da precaução, como forma de tentar evitar danos maiores à natureza e à saúde humana. Princípio este muito usado por países industrializados e de primeiro Mundo, mas que nem sempre é aplicado corretamente em termos de comércio entre Brasil e exterior, e que é rigorosamente usado nos campos de atuação nas relações comerciais exterior - Brasil.

Por meio destas relações comerciais comprova-se uma grande inobservância às normas vigentes no Brasil, onde, por exemplo, a rotulagem de alimentos contendo organismos geneticamente modificados é obrigatória, enquanto que o produto brasileiro perde mercado para o produto importado, não só pela grande concorrência, mas também pela falta da obrigatoriedade da rotulação destes produtos, gerando uma maior confiança por parte do consumidor em produtos importados, por não confiar totalmente em produtos oriundos da modificação genética.

O Código de Defesa do Consumidor trata da questão da responsabilidade do fornecedor, em seu art. 10, quando este coloca no mercado produtos ou serviços que saiba ou deveria saber apresentar alto grau de periculosidade, nocividade à saúde ou segurança. No caso em pauta, é preciso ter atenção redobrada, usando o máximo possível do princípio da precaução ou da prevenção, como é conhecido pelo ramo do direito ambiental, pois nem a comunidade científica pode precisar todos os seus efeitos decorrentes $(12,13,24,31)$. 
Uma vez garantido o acesso à informação sobre a presença de ingredientes oriundos de organismos geneticamente modificados, conforme normatizado pelo Decreto n. 4.680 , de 24.4.2003, o consumidor passará a exercitar o direito de escolha, revelando a real aceitação da população quanto a esses produtos. Estudos realizados em diversos países que comercializam alimentos derivados de organismos geneticamente modificados concluíram que a repulsa demonstrada pela população, parece estar muito mais relacionada à falta de oportunidade do exercício de um direito de escoIha do que com o próprio fator negativo dos alimentos geneticamente modificados $(1,6,7,15,30,32,35,36)$.

Quanto aos impactos ambientais que possam ser causados, a própria constituição federal é clara e precisa no que tange à integridade do patrimônio genético, assim como prescreve que as condutas e atividades que sejam lesivas ao meio ambiente serão penalizadas, seja 0 infrator pessoa física, seja pessoa jurídica (tendo em vista que a Lei n. 9.605/96 trouxe a inovação da possibilidade da responsabilidade criminal da pessoa jurídica), sem levar em conta, neste caso, se o infrator reparou os danos causados. Tais impactos podem ser previstos de antemão, como é o caso da erosão da diversidade genética e da poluição do solo diante a contaminação dos pesticidas que tendem a ser cada vez mais fortes devido ao aumento da resistência das plantas.

Seguido das conseqüências dos impactos ambientais, imperioso se faz lembrar que ainda não são conhecidos os efeitos que poderão ser gerados à espécie humana, em que pese os estudos realizados pela comunidade científica, sendo que tais efeitos poderão ser visados apenas em relação às próximas gerações.

Diante disto, se faz cogente a implantação de uma fiscalização mais rigorosa no âmbito da segurança alimentar, assim como a elaboração de leis que sejam mais eficazes para tal controle, para que o uso indevido dos organismos geneticamente modificados não seja feito indiscriminadamente por qualquer empresa, assim como normatizar o problema da importação de produtos contendo organismos geneticamente modificados, para que tais produtos possam competir com igualdade com os produtos nacionais.

Enquanto não houver conhecimento suficiente a respeito de tal tecnologia, há o dever de agir com cautela, dentro dos princípios constitucionais e ambientais para que a saúde humana não seja posta em perigo, ao mesmo tempo em que tais obstáculos não devem intimidar os estudos contributivos deste tipo de tecnologia, a despeito da possibilidade de encontrar novas maneiras de manejar a biotecnologia, sem que esta interfira na saúde humana e do meio ambiente.

Tendo em vista a gama de aspectos considerados no contexto da abordagem dos organismos geneticamente modificados, coloca-se 0 de- 
safio em estabelecer uma legislação equilibrada e compatível, em primeiro lugar garantindo a proteção do consumidor, o qual é o elo mais frágil dessa cadeia, porém discernindo aspectos tecnológicos e/ou burocráticos que possam constituir entraves ao desenvolvimento científico, tecnológico e econômico do País.

\section{AGRADECIMENTOS}

Este trabalho contou com o apoio de docentes vinculados ao Centro Colaborador em Vigilância Sanitária - Faculdade de Saúde Pública - USP (CECOVISA/USP), através do Convênio CA no 06/99-44-ANVS/MS, processo USP no 2001.1.1048.6.9, como parte do projeto de desenvolvimento de transferência tecnológica.

\section{REFERÊNCIAS}

1. AHMED FE. Detection of genetically modified organisms in foods. Trends in Biotechnology 2002; 20(5): 215-23.

2. ALMEIDA MCL. A responsabilidade civil na produção de organismos geneticamente modificados. Revista Direito Mackenzie 2000; 2(1):103-17.

3. ANKLAM E, BATTAGLIA R. Food analysis and consumer protection. Trends in Food Science \& Technology 2001; 12:197-202.

4. ANTONOPOULOU $L$, van MEURS $P$. The precautionary principle within European Union public health policy. The implementation of the principle under conditions of supranationality and citizenship. Health Policy 2003; 66(2):179-197.

5. ARAÚJO LEB. A Bioética em discussão: O caso da soja transgênica. Revista Direito, Santa Cruz do Sul. 2001.15:29-38.

6. BAKER GA, BURNHAM TA. The market for genetically modified foods: consumer characteristics and policy implications. International Food and Agribusiness Management Review 2002; 4:351-60.

7. BARLING D, VRIEND $H$, CORNELESE JA, EKSTRAND B, HECKER EFF, HOWLETT JH, JENSEN JH, LANG T, MAYER S, STAER KB, TOP R. The social aspects of food biotechnology: a European view. Environmental Toxicology and Pharmacology 1999; 7: 85-93.

8. BELZILE FJ. Transgenic, tranplastomic and other genetically modified plants: a Canadian perspective. Biochimie 2002; 84:1 111-18.

9. BERTOLLA F, SIMONET P. Horizontal gene transfers in the environment: natural transformation as a putative process for gene transfers between transgenic plants and microorganisms. 1999; Res. Microbiol. 150: 375-84. 
10. CERDA H, WRIGHT DJ. Could resistance to transgenic plants produce a new species of insect pests? Agriculture, Ecosystems and Environment 2002; 91:1-3.

11. CHARGELEGUE D, OBREGON P, DRAKE PMW. 2001. Transgenic plants for vaccine production: expectations and limitations. Trends in Plant Science, 6(11):495-6

12. CODEX ALIMENTARIUS COMISSION. Consideration of the elaboration of standards, guidelines or other principles for foods derived from biotechnology. World Health Organization. Chiba, Japan, 14-17-March 2000.

13. CUSTÓDIO HB. Direito do consumidor e os organismos geneticamente modificados. Revista de Direito Ambiental 2002; 27:127-65.

14. DALLARI SG, VENTURA, DF. O princípio da precaução: dever do Estado ou protecionismo disfarçado? São Paulo em Perspect. 2002; 16(2):53-63.

15. DAVIES KG. What makes genetically modified organisms so distasteful? Trends in Biotechnology 2001;19(10):424-27.

16. DUIJN GV, BIERT RV, BLEEKER-MARCELIS H, PEPPELMAN H, HESSIN M. Detection methods for genetically modified crops. Food Control 1999; 10:375-78.

17. FONTES EMG. Legal and regulatory concerns about transgenic plants in Brazil. Journal of Invertebrate Pathology 2003; 83(2):100-03.

18. FRANKEN E, TEUSCHEL U, HAIN R. Recombinant proteins from transgenic plants. Current Opinion in Biotechnology 1997; 8:411-16.

19. GACHET E, MARTIN GG, VIGNEAU F, MEYER G. Detection of genetically modified organisms (GMOs) by PCR: a brief review of methodologies available. Trends in Food Science \& Technology 1998; 9:380-88.

20. GOLDSTEIN BD. The precautionary principle also applies to public health actions. Am J Public Health 2001; 91(9):1359-61.

21. KANIEWSKI WK, THOMAS PE. Field testing of virus resistant transgenic plants. Seminars in Virology 1993; 4:389-96.

22. KURLAND J. The heart of the precautionary principle in democracy. Public Health Rep 2002; 117:498-500.

23. LACK G. Clinical risk assessment of GM foods. Toxicology letters 2002. 127: $337-340$.

24. MACEDO AAM. Produtos Transgênicos e o direito à informação do consumidor. Ciênc. Direito: R. jur. da FIC-UNAES. Campo Grande-MS. 1998/ 1999; 2:11-34.

25. MATZKE MA, MATZKE AJM. Homology-dependent gene silencing in transgenic plants: what does it really tell us? TIG 2000; 11(1):1-3. 
26. MEYER R. Development and application of DNA analytical methods for the detection of GMOs in food. Food Control 1999; 10:391-99.

27. MYERS N. The precautionary principle puts values first. Bulletin of Science, Technology \& Society 2002; 22(3): 210-19.

28. MITTEN DH, MACDONALD R, KLONUS D. Regulation of foods derived from genetically engineered crops. Current Opinion in Biotechnology 1999; 10:298-302.

29. MORRIS J. The relationship between risk analysis and the precautionary principle. Toxicology 2002; 181-182:127-130.

30. MOSES V. Biotechnology products and European consumers. Biotechnol Adv 1999; 17:647-678.

31. NERY JUNIOR N. Rotulagem dos alimentos geneticamente modificados. Revista dos Tribunais 2002; 795:41-54.

32. NOUSSAIR C, ROBIN S, RUFFIEUX B. Do consumers not care about biotech foods or do they jus not read the labels? Economic Letters 2002; 75:47-53.

33. NODARI RO, GUERRA MP. Plantas transgênicas e seus produtos: impactos, risco e segurança alimentar. (Biossegurança de Plantas Transgênicas). Revista de Nutrição da PUCCAMP - Campinas 2003; 16(1):105-16.

34. OECD 1992 Biotechnology, Agriculture and Food (93.92.03.1) ISBN 9264-13725-4.

35. ODA LM, SOARES BEC. Genetically modified foods: economic aspects and public acceptance in Brazil. Trends in Biotechnology 2000; 18(5):18890 .

36. PAARLBERG RL. The real threat to GM crops in poor countries: consumer and policy resistance to GM foods in rich countries. Food Policy 2002; 27: $247-50$.

37. ROBINSON J. Ethics and transgenic crops: a review. Electronic Journal of Biotechnology 1999; 2(2):71-81.

38. SAND PH. The precautionary principle: A European perspective. Human and Ecological Risk Assessment 2000; 6(3):445-58.

39. SCUTT CP, ZUBKO E, MEYER P. Techniques for the removal of marker genes from transgenic plants. Biochimie 2002; 84:1119-26.

40. SHAH DM, ROMMENS CMT, BEACHY RN. Resistance to diseases and insects in transgenic plants: progress and applications to agriculture. Tibtech 1995; 13:362-68.

41. STAM M, MOL JNM, KOOTER JM. The silence of genes in transgenic plants. Ann. Rev. of Botany1997; 79:3-12. 
42. STRAND R. The role of risk assessments in the governance of genetically modified organisms in agriculture. Journal of Hazardous Materials 2001; 86:187-204.

43. SU HY. Taiwan's GM foods labeling legislation - a review. Trends in Food Science \& Technology 2001; 12:465-68.

44. TICKNER, J.A, RAFFENSPERGER C. The precautionary principle: A framework for sustainable Business Decision-making. Corporate Environmental Strategy 1998;(5)4: 75-82.

45. WAL JM. Biotechnology and allergic risk. Rev. Fr. Allergol Immunol Clim. 2001; 41:36-41.

46. WISNIEWSKI JP, FRANGNE N, MASSONNEAU A, DUMAS C. Between myth and reality: genetically modified maize, an example of a sizeable scientific controversy. Biochimie 2002; 84:1095-1103. 